\title{
Consumer segmentation based on the level and structure of fruit and vegetable intake: an empirical evidence for US adults from the National Health and Nutrition Examination Survey (NHANES) 2005-2006
}

\author{
Tetyana Demydas* \\ Institute of Agricultural Policy and Market Research, Justus Liebig University Giessen, Senckenbergstr. 3, \\ 35390 Giessen, Germany
}

Submitted 14 May 2010: Accepted 8 December 2010: First published online 28 January 2011

\begin{abstract}
Objective: To identify consumption patterns of fruit and vegetables within a representative sample of US adults with a focus on degree of produce processing and to explore sociodemographic, lifestyle and nutritional profiles associated with these patterns.

Design: Cross-sectional analysis. Fruit and vegetable (F\&V) consumption data were collected using two non-consecutive $24 \mathrm{~h}$ recalls. For the purpose of the study, F\&V intakes were aggregated into seven subgroups indicating degree of processing, which afterwards were used as inputs into cluster analysis.

Setting: The 2005-2006 National Health and Nutrition Examination Survey.

Subjects: The sample consisted of 2444 adults aged 20-59 years.

Results: Total average F\&V intake of the adults was below the recommended level. Thereby, $20 \%$ of the respondents consumed fruit only in the form of juice. Three F\&V consumption patterns were identified: 'low-intake F\&V consumers' ( $74 \%$ of respondents), 'consumers of healthier F\&V options' (13\%) and 'intensive fruit juice consumers' (13\%). These groups differed markedly in terms of their sociodemographic, lifestyle and health characteristics, such as gender, age, race/ ethnicity, education, smoking, weight status, etc. Differences in nutrient profiles were also found, with the 'consumers of healthier F\&V options' showing better nutritional quality compared with other clusters.

Conclusions: Only a small share of US adults combines high F\&V intakes with healthier F\&V options that lead to a better nutritional profile. This raises discussion about a need to deliver more specific F\&V promotion messages, including advice on healthier preparation methods, especially for the specific population groups.
\end{abstract}

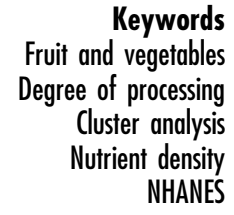

Scientific evidence supports an important role of fruit and vegetables (F\&V) as naturally healthy, nutrient-dense and low-energy foods, in a balanced diet and in prevention of many chronic diseases ${ }^{(1-3)}$. A large amount of literature has investigated the fruit and vegetable $(\mathrm{F} \& \mathrm{~V})$ intakes of populations and their correspondence to the existing recommendations ${ }^{(4-7)}$. Thereby, F\&V have most often been considered as a combined variable or differentiated by botanical characteristics, e.g. citrus fruits, berries, dark green vegetables and legumes. However, there has been less focus on the actual F\&V consumption patterns, i.e. the way $F \& V$ are incorporated into diets, which certainly contributes to the overall diet healthiness. Thus, one might choose to eat F\&V in their natural low-energy form, as well as use cooking techniques such as deep-fat frying, serving with high-fat dressings or sauces or including in high-fat mixtures, which greatly increase the energy and fat content in the dish and thus reduce the healthiness of the produce $^{(8)}$. Canned F\&V may contribute to the rise of total energy consumed, when prepared with added sugar and heavy syrups, and may also contain added salt. Although fruit juice is rich in a number of micronutrients, it loses the fibre present in a whole fruit and is often a source of additional energy. Moreover, a whole fruit provides higher satiety than does juice, and may therefore contribute to weight management ${ }^{(9)}$. Consequently, a '5-a-day' message aimed at encouragement of F\&V intake might be of little support to health in the case of insufficient attention to the way $\mathrm{F} \& \mathrm{~V}$ are incorporated into diets. In this context, defining the $\mathrm{F} \& \mathrm{~V}$ intake patterns among the population is of special interest. Cluster analysis presents a methodological approach widely used for identification of dietary patterns as it groups individuals with similar characteristics into homogeneous, mutually exclusive $\operatorname{groups}^{(10-13)}$. 
The main objective of the present study is to identify $\mathrm{F} \& \mathrm{~V}$ intake patterns of US adults on the basis of the degree of processing of the consumed $\mathrm{F} \& \mathrm{~V}$ using a clustering procedure. Specifically, the current study presents: (i) F\&V classification with respect to their degree of processing and description of intakes from the created subgroups; (ii) derivation of F\&V consumption patterns; (iii) exploration of sociodemographic and behavioural differences across clusters; and (iv) comparison of their nutritional profiles.

\section{Methods}

\section{Study sample and survey data}

The US National Health and Nutrition Examination Survey (NHANES) 2005-2006, with responses from adults of 20-59 years of age, who were non-pregnant and non-lactating and had reliable $2 \mathrm{~d}$ dietary information and $\mathrm{F} \& \mathrm{~V}$ intake data, provided data for the analysis. The final study sample comprised 2444 persons (87\% of the NHANES 2005-2006 adult sample). Details on the design of the NHANES survey are given elsewhere ${ }^{(14,15)}$. Briefly, the NHANES is a programme of studies conducted by the National Center for Health Statistics (NCHS) of the Centers for Disease Control and Prevention designed to assess the health and nutritional status of adults and children in the USA. It is a nationwide probability sample of the population selected via complex multistage probability techniques. Sample weights and sample design variables that compensate for different probability of selection, non-response and post-stratification should be used to obtain representative results. F\&V consumption information was collected from each respondent by means of two non-consecutive $24 \mathrm{~h}$ dietary recalls. Total nutrient intakes were calculated for each interviewee by NCHS and were available in the data set. Data on smoking status and other behavioural characteristics were obtained by standardized questionnaires. Body weight and height were measured by trained specialists.

\section{Fruit and vegetable classification}

The NHANES 2005-2006 provides detailed information about consumed $\mathrm{F} \& \mathrm{~V}$, including their form (i.e. whole, juice), degree of processing (i.e. cooked, canned) and additional ingredients. The intakes of $F \& V$ as a part of composite dishes, e.g. soups, sandwiches, stews and pizzas, can be accounted for. Data preparation covered screening the reported $2 \mathrm{~d} F \& \mathrm{~V}$ intakes and grouping them into subgroups with respect to the degree of processing using the codes of the Food and Nutrient Database for Dietary Studies of the US Department of Agriculture (USDA) ${ }^{(16)}$. In total, 430 codes for fruit and 1566 codes for vegetable groups including legumes were available. Table 1 presents the description of the created subgroups. In the present study, fruits refer to whole fruit eaten in all forms and 100\% fruit juice. The following fruit subgroups were created: raw, juice and canned/ frozen/dried/desserts. More detailed subdivision was not feasible because of: (i) the initial food coding in the data set (i.e. no consistent distinction between canned, cooked and frozen produce); and (ii) a very small number of persons who reported consumption of dried fruits and fruit desserts. The vegetable group consists of darkgreen, deep-yellow produce, tomatoes, other vegetables, legumes, potatoes (including fried potatoes but excluding potato chips) and other starchy vegetables in all preparation forms. Inclusion of legumes and potatoes with other starchy tubers into the group of vegetables varies among studies ${ }^{(17)}$. Owing to the fact that these foods constitute a part of the Food Guide Pyramid recommendations about vegetable consumption ${ }^{(18)}$, they were classified into the vegetable category. The following subgroups were created: raw vegetables, consumed with and without dressings; cooked vegetables, served without dressings, creams and non-vegetable items; vegetables in mixed dishes, including those served with creams, dressings and non-vegetable items; and fried vegetables.

Table 1 Classification of F\&V by degree of processing

\begin{tabular}{ll}
\hline Groups & Examples of foods in subgroup classification* \\
\hline $\begin{array}{l}\text { Fruit } \\
\text { Raw } \\
\text { Juice } \\
\text { Canned/frozen/dried/ } \\
\text { desserts }\end{array}$ & $\begin{array}{l}\text { Orange; papaya; plum; fruit salad without dressing } \\
\text { Apple juice, fresh; lemon juice, bottled; tangerine juice, canned } \\
\text { mango, pickled; blackberries, frozen; banana chips; pear, dried, cooked with sugar; lime soufflé; fruit salad } \\
\text { mith salad dressing or mayonnaise }\end{array}$ \\
$\begin{array}{l}\text { Vegetables } \\
\text { Raw }\end{array}$ & $\begin{array}{l}\text { Broccoli, raw; spinach salad, no dressing; cucumber salad with creamy dressing; artichoke salad in oil } \\
\text { Cooked }\end{array}$ \\
$\begin{array}{l}\text { Beet greens, cooked, fat not added in cooking; tomatoes, from fresh produce, broiled; mushrooms, stuffed; } \\
\text { white potato, baked, peel not eaten; green plantains, boiled }\end{array}$ \\
$\begin{array}{l}\text { Vegetable combinations, cooked, with pasta; carrots, tomato beef rice soup, prepared with water; potato from } \\
\text { In mixed dishes } \\
\text { Puerto Rican beef stew, with gravy; corn, cooked, from fresh produce, with cream sauce, made with milk; } \\
\text { bean and rice soup }\end{array}$ \\
Potato pancake; aubergine, batter dipped, fried; white potato, french fries, from frozen produce, deep fried
\end{tabular}

F\&V, fruit and vegetables.

*The list of foods is taken from Food and Nutrient Database for Dietary Studies and is not exhaustive of each subgroup. 


\section{Nutritional quality}

To examine nutritional profiles associated with the identified $F \& V$ intake patterns, an index of nutritional quality (INQ) was applied. This approach allows the analysis of nutritional adequacy of an individual within the energy needs. The INQ is defined as the ratio of nutrient density to the amount of this nutrient recommended for the maintenance of good health within a given energy requirement ${ }^{(21,22)}$. The actual densities of the selected nutrients were calculated on the basis of the person's $2 \mathrm{~d}$ average intakes ${ }^{(11,19,20)}$. The nutrient densities based on the recommendations of the USDA Food Guide ${ }^{(23)}$ served as a reference. Therefore,

$$
\begin{aligned}
\text { INQ }= & \text { nutrient density } / \text { recommendations of USDA } \\
& \text { Food Guide per } 4184 \mathrm{~kJ}(1000 \mathrm{kcal}) .
\end{aligned}
$$

INQ was calculated separately for each of the selected key nutrients related to $\mathrm{F} \& \mathrm{~V}$ intake (i.e. dietary fibre, $\mathrm{K}$, $\mathrm{Ca}, \mathrm{Mg}$, vitamins $\mathrm{C}$ and $\mathrm{A}$ ) and to undesirable health factors (i.e. total fat, total SFA, total sugar, Na, cholesterol). INQ values $>1.0$ may be seen as desirable for fibre, $\mathrm{K}, \mathrm{Ca}, \mathrm{Mg}$ and vitamins $\mathrm{C}$ and $\mathrm{A}$, and as undesirable for fats, sugar, $\mathrm{Na}$ and cholesterol.

\section{Statistical methods}

Statistical analyses were performed using the Statistical Package for the Social Sciences statistical software package version $17 \cdot 0$ (SPSS Inc., Chicago, IL, USA). To identify groups of subjects with similar F\&V eating patterns, a twostage clustering procedure, advocated in the literature because of higher validity of cluster solution, was applied $^{(24)}$. The $2 \mathrm{~d}$ average intakes of the created $\mathrm{F} \& \mathrm{~V}$ subgroups were used as continuous inputs. Hierarchical cluster analysis with squared Euclidean distance was run to determine the number of clusters and was followed by K-means clustering. An optimal number of clusters was decided on the basis of inspection of the change in agglomeration coefficients. Because all variables were measured at the same scale, they were not standardized before the analysis. Reliability of the cluster solution was checked by performing the procedure multiple times, changing algorithms and methods, as well as by splitting the sample into halves and analysing each one independently $^{(25)}$. The stability of the cluster solution was tested through discriminant analysis. Distribution differences in sociodemographics, lifestyles and health status associated with the derived groups were examined with the $\chi^{2}$ test. ANOVA with least significant difference test for multiple comparisons was applied to assess mean differences among clusters by $\mathrm{F} \& \mathrm{~V}$ intakes. All $P$ values were twosided $(P<0 \cdot 05)$. Except clustering, all statistical analyses were performed on the weighted sample ${ }^{(10)}$. Means and standard errors were estimated in an SPSS $17 \cdot 0$ Complex Samples module that allowed the use of sampling weights and sample design variables and, thus, the production of representative estimates for the selected group of the civilian, non-institutionalized US population.

\section{Results}

\section{Fruit and vegetable consumption in the whole sample}

Total daily average $\mathrm{F} \& \mathrm{~V}$ intake of adults amounts to $359 \mathrm{~g} /$ person, taking fruit juice into account, and $285 \mathrm{~g}$ after excluding juice (Table 2), which is below the WHO recommended minimum of $400 \mathrm{~g} \mathrm{~F} \& \mathrm{~V} / \mathrm{d}$ excluding

\begin{tabular}{|c|c|c|c|c|c|c|c|c|c|}
\hline \multirow[b]{2}{*}{ Groups } & \multicolumn{2}{|c|}{$\begin{array}{c}\text { Low-intake F\&V } \\
\text { consumers (n 1802) }\end{array}$} & \multicolumn{2}{|c|}{$\begin{array}{l}\text { Consumers of healthier } \\
\text { F\&V options ( } n \text { 323) }\end{array}$} & \multicolumn{2}{|c|}{$\begin{array}{l}\text { Intensive fruit juice } \\
\text { consumers (n 319) }\end{array}$} & \multirow[b]{2}{*}{$P$ valuet } & \multicolumn{2}{|c|}{ All $(n$ 2444) } \\
\hline & Mean & SE & Mean & SE & Mean & SE & & Mean & SE \\
\hline \multicolumn{10}{|l|}{ Fruit } \\
\hline Raw & $77 \cdot 1^{a}$ & $2 \cdot 4$ & $276 \cdot 3^{b}$ & $8 \cdot 4$ & $134 \cdot 1^{c}$ & $9 \cdot 9$ & 0.000 & $139 \cdot 3$ & $6 \cdot 5$ \\
\hline Juice & $112 \cdot 8^{a}$ & $5 \cdot 4$ & $143 \cdot 7^{b}$ & $12 \cdot 4$ & $427 \cdot 6^{c}$ & $21 \cdot 1$ & 0.000 & $236 \cdot 5$ & $8 \cdot 9$ \\
\hline $\begin{array}{l}\text { Canned/frozen/dried/ } \\
\text { desserts }\end{array}$ & $58 \cdot 5$ & $6 \cdot 2$ & $52 \cdot 9$ & $7 \cdot 0$ & $54 \cdot 6$ & $8 \cdot 3$ & 0.775 & $56 \cdot 9$ & $5 \cdot 0$ \\
\hline \multicolumn{10}{|l|}{ Vegetables } \\
\hline Raw & $84 \cdot 5^{a}$ & $3 \cdot 6$ & $116 \cdot 6^{b}$ & $8 \cdot 8$ & $94 \cdot 4^{a}$ & $7 \cdot 5$ & 0.023 & $90 \cdot 9$ & $3 \cdot 6$ \\
\hline Cooked & $96 \cdot 6^{\mathrm{a}}$ & 3.9 & $139 \cdot 8^{b}$ & $6 \cdot 5$ & $112 \cdot 6^{a}$ & $10 \cdot 5$ & 0.000 & $105 \cdot 2$ & $4 \cdot 1$ \\
\hline In mixed dishes & $77 \cdot 5$ & $4 \cdot 3$ & $92 \cdot 7$ & $9 \cdot 2$ & $78 \cdot 4$ & $8 \cdot 4$ & 0.302 & $79 \cdot 7$ & $4 \cdot 3$ \\
\hline Fried & $53 \cdot 0^{a}$ & $2 \cdot 4$ & $42 \cdot 7^{b}$ & $3 \cdot 2$ & $57 \cdot 7^{a}$ & $4 \cdot 4$ & 0.022 & $52 \cdot 7$ & $1 \cdot 8$ \\
\hline Total F\&V & $255 \cdot 2^{a}$ & $4 \cdot 7$ & $599 \cdot 1^{b}$ & $16 \cdot 5$ & $703 \cdot 7^{c}$ & $25 \cdot 5$ & 0.000 & $359 \cdot 4$ & $10 \cdot 6$ \\
\hline $\begin{array}{l}\text { Total F\&V, excluding } \\
\text { fruit juice }\end{array}$ & $233 \cdot 2^{a}$ & $5 \cdot 0$ & $552 \cdot 6^{\mathrm{b}}$ & $13 \cdot 7$ & $284 \cdot 0^{c}$ & $14 \cdot 0$ & 0.000 & $285 \cdot 1$ & $8 \cdot 9$ \\
\hline $\begin{array}{l}\text { F\&V density } \\
\text { (g/1000 kcal }) \ddagger\end{array}$ & $129 \cdot 2^{a}$ & $2 \cdot 4$ & $300 \cdot 1^{b}$ & $12 \cdot 1$ & $320 \cdot 8^{b}$ & $16 \cdot 8$ & 0.000 & $177 \cdot 1$ & $4 \cdot 8$ \\
\hline
\end{tabular}

Table 2 Intakes (g) of F\&V by degree of processing across the clusters of adults from NHANES 2005-2006*

F\&V, fruit and vegetables; NHANES, National Health and Nutrition Examination Survey.

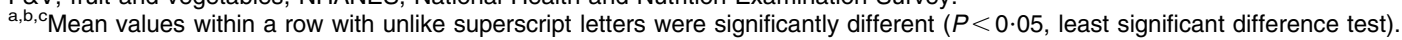

${ }^{*}$ Data are weighted to be representative of the population. Multiple answers were possible. Persons who reported no consumption of a particular subgroup were not considered during mean calculation.

$+P$ value among groups (one-way ANOVA)

$\ddagger 1 \mathrm{kcal}=4 \cdot 184 \mathrm{~kJ}$. 
potatoes and other starchy produce ${ }^{(1)}$. Fruit juice and raw fruits were the main contributors to the fruit group, with 237 and $139 \mathrm{~g} /$ person on average, respectively. In the vegetable group, adults reported on average the highest intakes of cooked $(105 \mathrm{~g})$ and raw vegetables $(91 \mathrm{~g})$. Fruits in the 'canned/frozen/dried/desserts' form, as well as vegetables in mixed dishes and fried, were less important in terms of absolute amounts. Furthermore, as shown in the Appendix (Fig. A1), 20\% of the interviewees incorporated fruit into their diets only in the form of juice on both recall days. About $81 \%$ of the adults consumed vegetables in more than one predefined form.

\section{Cluster solutions for fruit and vegetable intake patterns}

Three consumption patterns were identified as the most adequate representation of the combinations of $F \& V$ subgroups in the diet of adults. Further splitting of the clusters led to a smaller heterogeneity among them and did not result in additional information about the intake patterns. The discriminant function analysis performed on the derived clusters also indicated a good stability of the chosen three-cluster solution. The percentage of correct classifications, i.e. the 'hit ratio', was 93.0\%.
All input variables (i.e. created F\&V subgroups), except fruit as 'canned/frozen/dried/desserts' and vegetables in mixed dishes, contributed significantly to the formation of clusters. Tables 2 and 3 present data for the three clusters on F\&V intakes, as well as on sociodemographic and behavioural characteristics.

The first segment represents the largest group of 1802 persons ( $74 \%$ of adults). They are characterized by low intakes from all the F\&V subgroups with a total average intake of $255 \mathrm{~g} / \mathrm{d}$. Therefore, the cluster may be described as 'low-intake F\&V consumers'. A large share of these individuals reported to have a lower education, to smoke and to eat out often/very often. Only one quarter of them evaluated their own diet as excellent/very good. The overweight/obesity rate was $67 \cdot 4 \%$, the highest across the groups $(P=0 \cdot 047)$.

The second cluster consists of 323 individuals (13\% of adults). Participants of this group consumed on average about $600 \mathrm{~g}$ of $\mathrm{F} \& \mathrm{~V} / \mathrm{d}$. Compared with other segments, they stated higher consumption of raw fruits $(P=0 \cdot 000)$ and raw vegetables $(P=0 \cdot 023)$, as well as of cooked vegetables without dressings $(P=0 \cdot 000)$. The intake of fried vegetables was significantly lower here $(P=0 \cdot 022)$. On the basis of this, the cluster was labelled 'consumers

Table 3 Sociodemographic and behavioural characteristics across the clusters of adults from NHANES 2005-2006*

\begin{tabular}{|c|c|c|c|c|c|}
\hline & $\begin{array}{l}\text { Low-intake F\&V } \\
\text { consumers ( } n \text { 1802) }\end{array}$ & $\begin{array}{l}\text { Consumers of healthier } \\
\text { F\&V options }(n 323)\end{array}$ & $\begin{array}{l}\text { Intensive fruit juice } \\
\text { consumers }(n 319)\end{array}$ & & All $(n$ 2444) \\
\hline Characteristics & $\%$ & $\%$ & $\%$ & $P$ valuet & $\%$ \\
\hline Gender & & & & 0.012 & \\
\hline Male & $47 \cdot 8$ & $45 \cdot 3$ & $62 \cdot 2$ & & $49 \cdot 2$ \\
\hline Female & $52 \cdot 2$ & $54 \cdot 7$ & $37 \cdot \overline{8}$ & & $50 \cdot \overline{8}$ \\
\hline Age (years) & & & & 0.000 & \\
\hline $20-39$ & $50 \cdot 6$ & $32 \cdot 5$ & $58 \cdot 4$ & & $49 \cdot 0$ \\
\hline $40-59$ & $49 \cdot 4$ & $67 \cdot 5$ & $41 \cdot 6$ & & $51 \cdot 0$ \\
\hline Marital status & & & & 0.021 & \\
\hline Married & $55 \cdot 4$ & $66 \cdot 2$ & $50 \cdot 9$ & & $56 \cdot 4$ \\
\hline Not married & $44 \cdot 6$ & $33 \cdot 8$ & $49 \cdot 1$ & & $43 \cdot 6$ \\
\hline Race/ethnicity & & & & 0.025 & \\
\hline Mexican American/other races & $16 \cdot 9$ & $18 \cdot 5$ & $21 \cdot 7$ & & $17 \cdot 7$ \\
\hline Non-Hispanic Black & $12 \cdot 2$ & $7 \cdot 5$ & $16 \cdot 9$ & & $12 \cdot 1$ \\
\hline Non-Hispanic White & $70 \cdot 9$ & $74 \cdot 0$ & $61 \cdot 4$ & & $70 \cdot 1$ \\
\hline Education & & & & 0.000 & \\
\hline High school & $40 \cdot 1$ & $22 \cdot 5$ & $33 \cdot 2$ & & $36 \cdot 7$ \\
\hline Some college or AA degree & $35 \cdot 4$ & $33 \cdot 8$ & $36 \cdot \overline{4}$ & & $35 \cdot 3$ \\
\hline College graduation or above & $24 \cdot 5$ & $43 \cdot 8$ & $30 \cdot 4$ & & $28 \cdot 0$ \\
\hline Income (\$US/year) & & & & 0.058 & \\
\hline$<45000$ & $36 \cdot 9$ & $29 \cdot 2$ & $43 \cdot 4$ & & $36 \cdot 6$ \\
\hline$>45000$ & $63 \cdot 1$ & $70 \cdot \overline{8}$ & $56 \cdot 6$ & & $63 \cdot 4$ \\
\hline Own diet evaluation & & & & 0.000 & \\
\hline Excellent/very good & $25 \cdot 2$ & $53 \cdot 0$ & $32 \cdot 7$ & & $30 \cdot 0$ \\
\hline Good & $41 \cdot 3$ & $32 \cdot 2$ & $38 \cdot 0$ & & $39 \cdot 6$ \\
\hline Fair/poor & $33 \cdot 6$ & $14 \cdot 7$ & $29 \cdot 3$ & & $30 \cdot 4$ \\
\hline Eating out & & & & 0.019 & \\
\hline Never/seldom & $11 \cdot 8$ & $19 \cdot 5$ & $16 \cdot 9$ & & $13 \cdot 5$ \\
\hline Sometimes & 31.5 & $38 \cdot 0$ & $31 \cdot 9$ & & 32.5 \\
\hline Often/very often & $56 \cdot 7$ & $42 \cdot 4$ & $51 \cdot 2$ & & $54 \cdot 0$ \\
\hline Smokers & $30 \cdot 0$ & $13 \cdot 2$ & $20 \cdot 7$ & 0.003 & $26 \cdot 5$ \\
\hline Overweight/obese $\left(\mathrm{BMI} \geq 25 \cdot 0 \mathrm{~kg} / \mathrm{m}^{2}\right)$ & $67 \cdot 4$ & $58 \cdot 6$ & $64 \cdot 2$ & 0.047 & $65 \cdot 7$ \\
\hline
\end{tabular}

NHANES, National Health and Nutrition Examination Survey; F\&V, fruit and vegetables; AA, associate of arts. ${ }^{*}$ Data are weighted to be representative of the population.

$+P$ value among groups ( $\chi^{2}$ test). 
of healthier F\&V options'. In comparison with the other groups, females, older respondents, married persons and individuals with higher education and household income constituted a large share of the segment. Over a half of the group (53\%) judged their own diet as excellent/very good. Moreover, the share of overweight/obese adults was the lowest here $(58 \cdot 6 \%)$.

The third cluster is a group of 319 persons (13\% of adults) whose F\&V consumption is characterized by a high share of fruit juice. Although their total $F \& V$ intake was over $700 \mathrm{~g} / \mathrm{d}$, exclusion of fruit juice from this calculation reduced the amount to only $284 \mathrm{~g}$. The cluster was named 'intensive fruit juice consumers'. Compared with other segments, males, younger interviewees, nonHispanic blacks and persons with lower household income were highly represented here. Overweight/obese individuals constituted $64 \cdot 2 \%$ of the cluster.

\section{Nutrient profiles of the clusters}

Figure 1 gives an overview of the nutritional adequacy among adults overall and across the clusters measured by INQ of eleven key nutrients. All three clusters with distinct $F \& V$ intake patterns showed a low nutritional quality with respect to the USDA Food Guide recommendations ${ }^{(23)}$. Overconsumption of undesirable nutrients (e.g. fats, Na) and insufficient consumption levels of desirable nutrients (e.g. fibre, Ca, vitamins $\mathrm{A}$ and $\mathrm{C}$ ) are clearly prevailing. However, in the cluster 'low-intake F\&V consumers', a greater share of the individuals seemed to have a worse nutritional profile in comparison with the other segments. A very small proportion of these persons complied with the recommendations for the considered nutrients. Although the pattern 'consumers of healthier F\&V options' was associated with a higher intake of healthy nutrients, the proportion of individuals with adequate densities of fats, $\mathrm{Na}$ and cholesterol was also low in this cluster. Compared with the other groups, a higher share of the 'intensive fruit juice consumers' could reach the recommendation on vitamin C. However, they had a lower adequacy in terms of sugar intake.

\section{Discussion}

The present study explored F\&V consumption patterns among adults in the USA with a special focus on the preparation method of the consumed produce. The basic motivation behind the study was that such healthy foods as $F \& V$ might not be consumed in a healthy way, but rather by using preparation techniques and additional ingredients that significantly reduce their dietary and health benefits. Therefore, it is of interest for public health policy to monitor such trends and to determine groups of individuals who might be targeted with more specific nutritional advice.

According to the results, US adults do not consume sufficient quantities of $\mathrm{F} \& \mathrm{~V}$, which is in line with previous research $^{(7,26,27)}$. Among the $\mathrm{F} \& \mathrm{~V}$ preparation forms explored in the study, fruit juice, raw fruits as well as vegetables cooked and eaten without dressings and in a raw form had the highest shares in the total average intake. Consumption of $\mathrm{F} \& \mathrm{~V}$ in other forms, e.g. fruit as 'canned/frozen/dried/desserts', vegetables in mixed dishes and fried, was lower. Notably, about $20 \%$ of the respondents reported consumption of fruit only in the form of juice. Such importance of fruit juice has been shown by other studies. According to the results from the NHANES 2003-2004, orange juice was the largest contributor to overall fruit intake in the USA ${ }^{(26)}$. Putnam et $a l^{(28)}$ also indicated a low variety in the fruit intake of Americans and showed that orange and apple juice, out of over sixty fruit products from food supply data, accounted for $25 \%$ of all fruit servings in 2000 . Results of our study suggest that high fruit juice consumption can be attributed to a particular group of adults named in the study as 'intensive fruit juice consumers' (13\% of adults). Especially younger individuals, predominantly males, non-Hispanic blacks and persons with lower household income tend to show this consumption pattern. While evaluating the impact of juice intake on diet and health, several aspects should be considered. First, it is important to bear in mind and to remind consumers
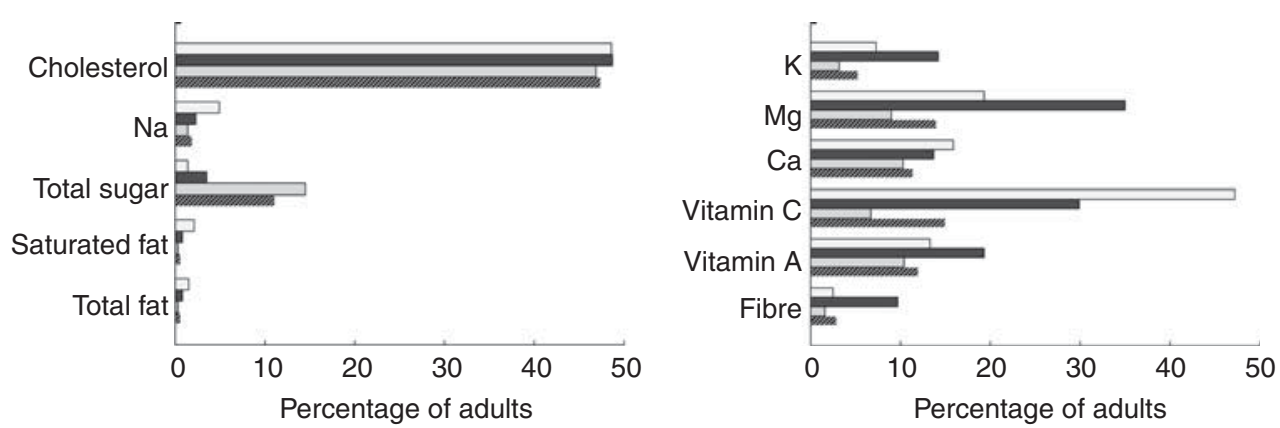

Fig. 1 Percentage of adults with adequate nutrient intakes ( $\square$, low-intake F\&V consumers, $n$ 1802; $\square$, consumers of healthier F\&V options, $n$ 323; $\square$, intensive fruit juice consumers, $n 319 ; \mathbb{N}$, all adults, $n 2444)$. Source: National Health and Nutrition Examination Survey 2005-2006. Recommendations of the Food Guide Pyramid of the US Department of Agriculture were used as a reference. They were reached if index of nutritional quality (INQ) was $<1$ for total fat, saturated fat, total sugar, Na and cholesterol, and if INQ was $>1$ for fibre, vitamins $\mathrm{A}$ and $\mathrm{C}, \mathrm{Ca}, \mathrm{Mg}$ and $\mathrm{K}$. 
that, although fruit juice is rich in micronutrients, it provides much less fibre than a whole fruit and can be a source of additional energy. The US Dietary Guidelines Advisory Committee emphasizes that no more than one of the three recommended fruit servings should come from fruit juice and the rest from whole fruit ${ }^{(29)}$. Second, the driving forces of a high juice intake need deeper investigation. Among others, the convenience aspect might play a determinative role in this decision. Consumers might also perceive juice as an extremely healthy and important component of their diet, and therefore 'the more, the better' rule is applied. They might also believe to be able to fulfil the F\&V recommendations solely with juice. In this respect, clearer F\&V promotional messages including a special notion on fruit juice could be beneficial.

The study also showed that the low-intake F\&V consumers' pattern constitutes a prevailing share of the adult population in the USA ( $74 \%$ of adults). This group had low intakes of all F\&V subgroups, especially of raw produce. Characteristics of the low-intake consumers (e.g. lower education, non-Hispanic black race, unhealthy lifestyles) are consistent with the results of previous studies $^{(7,15,28,30-32)}$. Bertail and Caillavet ${ }^{(33)}$, who studied heterogeneity of F\&V consumption patterns in France by disaggregating intakes into subgroups by preparation method, found that households with the lowest income and lower education level of the reference member tended to have the lowest total F\&V intakes and, furthermore, to consume less of raw $F \& V$ and more of canned and frozen fruits as well as to spend a higher budget share for vegetable-based convenience food. However, the segment comprised predominantly of more affluent consumers and those with higher education level was positively associated with consumption of fresh F\&V. In our study, adults with similar characteristics (e.g. higher education and income level, being older and married) formed the pattern 'consumers of healthier F\&V options' (13\% of adults). Compared with other clusters, a smaller share of these individuals was overweight or obese. Although the relationship between F\&V intake and obesity has been a focus of research, the results of investigations are contradictory ${ }^{(8,9,34)}$. Lin and Mentzer Morrison $^{(8)}$ found a negative association between fruit consumption and BMI, but no strong association with respect to vegetables. They stated that the key to these associations might be the way in which people tend to consume the produce. Investigation of the links between $\mathrm{F} \& \mathrm{~V}$ intake and body weight should further explore this issue.

Differences detected in the nutritional profiles of the segments can be partly attributed to amounts, as well as to preparation methods of F\&V. Associations between low F\&V consumption and inadequate intakes of micronutrients and fats found in the study are in line with previous research ${ }^{(35)}$. 'Intensive fruit juice consumers' could not meet the recommendations either, with the exception of a considerably higher adequacy of vitamin C intake. The pattern 'consumers of healthier F\&V options', rich in low-energy-dense options (e.g. raw produce, F\&V cooked and served without dressings), was associated with higher densities of healthy nutrients. However, the share of individuals with adequate intakes of unhealthy nutrients was still very low in this cluster. An explanation could be that $F \& V$ are not eaten as substitutes for higher energy foods. However, the present study did not look at this aspect closely and there is a potential for further research. Moreover, a combination of a higher F\&V intake with reduction of energy density in the diet is discussed in the literature with respect to its importance for weight management $^{(4)}$.

In interpreting our results, several methodological issues must be taken into account. First, since only $2 \mathrm{~d}$ dietary data were available, the question about the reliability of the characterization of the individual's usual intake may arise because of day-to-day variations in consumption. Another aspect is application of cluster analysis. Although it has an exploratory nature, this method has been widely applied for identification of population subgroups with distinct dietary patterns. In the present study, we additionally used discriminant analysis to confirm the stability of the chosen solution.

The study also has a number of strengths. First, the sample was population based, which allows inferences for the adult non-institutionalized population of the USA. An important advantage of the used data set is that it reflects $F \& V$ intakes from composite dishes (e.g. soup, pizza, sandwich). Omission of this information is considered to be a common problem leading to underreporting and bias in the studies on F\&V intake ${ }^{(36)}$. Overall, the study contributes to the investigation of $\mathrm{F} \& \mathrm{~V}$ consumption in the USA by taking into consideration not only amounts but also the preparation forms of the consumed produce.

In conclusion, our results show that different patterns of F\&V consumption exist among US adults, which contribute to the differences in their nutrient profiles. The study suggests a need to monitor the current consumption trends and especially the related disparities across age, ethnic and educational groups. The delivery of more specific F\&V promotion messages, including the focus on $\mathrm{F} \& \mathrm{~V}$ options of a higher nutritional value, healthier preparation methods and explicit substitution message, might be considered.

\section{Acknowledgements}

The author acknowledges the postgraduate funding from the Federal State of Hesse and the Justus Liebig University of Giessen (Germany) that supported the present study. There is no conflict of interest to declare. 


\section{References}

1. World Health Organization (2005) Fruit and Vegetables for Health. Report of a Joint FAO/WHO Workshop, 1-3 September 2004, Kobe, Japan. Geneva: WHO.

2. Van Duyn MA \& Pivonka E (2000) Overview of the health benefits of fruit and vegetable consumption for the dietetics professional: selected literature. J Am Diet Assoc 100, 1511-1521.

3. Steinmetz KA \& Potter JD (1996) Vegetables, fruit and cancer prevention: a review. J Am Diet Assoc 96, 1027-1039.

4. Dong D \& Lin BH (2009) Fruit and Vegetable Consumption by Low-Income Americans: Would a Price Reduction Make a Difference? Economic Research Report no. 70. Washington, DC: US Department of Agriculture, Economic Research Service.

5. Stark Casagrande S, Wang Y, Anderson C et al. (2007) Have Americans increased their fruit and vegetable intake? The trends between 1988 and 2002. Am J Prev Med 32, 257-263.

6. Serdula MK, Gillespie C, Kettel-Khan L et al. (2004) Trends in fruit and vegetable consumption among adults in the United States: behavioral risk factor surveillance system, 1994-2000. Am J Public Health 94, 1014-1018.

7. Krebs-Smith SM, Cook DA, Subar AF et al. (1995) US adults' fruit and vegetable intakes, 1989 to 1991: a revised baseline for the Healthy People 2000 objective. Am J Public Health 85, 1623-1629.

8. Lin BH \& Mentzer Morrison R (2002) Higher fruit consumption linked with lower body mass index. Food Rev 25, 28-32.

9. Tohill BC (2005) Dietary Intake of Fruit and Vegetables and Management of Body Weight. Background Paper for the Joint FAO/WHO Workshop on Fruit and Vegetables for Health, 1-3 September 2004, Kobe, Japan. Geneva: WHO.

10. Popkin BM, Barclay DV \& Nielsen SJ (2005) Water and food consumption patterns of US adults from 1999 to 2001. Obes Res 13, 2146-2152.

11. Pryer JA, Nichols R, Elliott P et al. (2001) Dietary patterns among a national random sample of British adults. J Epidemiol Community Health 55, 29-37.

12. Greenwood DC, Cade JE, Draper A et al. (2000) Seven unique food consumption patterns identified among women in the UK Women's Cohort Study. Eur J Clin Nutr 54, 314-320.

13. Wirfält E, Mattisson I \& Gullberg B (1999) Food patterns defined by cluster analysis and their utility as dietary exposure variables: a report from the Malmö Diet and Cancer Study. Public Health Nutr 3, 159-173.

14. Kant AK \& Graubard BI (2008) Ethnic and socioeconomic differences in variability in nutritional biomarkers. $\mathrm{Am} \mathrm{J}$ Clin Nutr 87, 1464-1471.

15. Dubowitz T, Heron M, Bird CE et al. (2008) Neighbourhood socioeconomic status and fruit and vegetable intake among whites, blacks, and Mexican Americans in the United States. Am J Clin Nutr 87, 1883-1891.

16. US Department of Health and Human Services, Centres for Disease Control and Prevention (2005) NHANES 2005-2006. Examination files, dietary interview (individual foods file), food codes documentation. http://www.cdc.gov/nchs/ nhanes/nhanes2005-2006/exam05_06.htm (accessed May 2010).

17. Bazzano LA (2005) Dietary Intake of Fruit and Vegetables and Risk of Diabetes Mellitus and Cardiovascular Diseases. Background Paper for the Joint FAO/WHO Workshop on
Fruit and Vegetables for Health, 1-3 September 2004, Kobe, Japan. Geneva: WHO.

18. US Department of Agriculture, Center for Nutrition Policy and Promotion (2005) The Food Guide Pyramid. Home and Garden Bulletin no. 252. Washington, DC: US Government Printing Office.

19. Siega-Riz AM, Popkin BM \& Carson T (2000) Differences in food patterns at breakfast by sociodemographic characteristics among a nationally representative sample of adults in the United States. Prev Med 30, 415-424.

20. Willett WC, Howe GR \& Kushi LH (1997) Adjustment for total energy intake in epidemiologic studies. Am J Clin Nutr 65, Suppl. 4, S1220-S1228.

21. Drewnowski A (2005) Concept of nutritious food: toward a nutrient density score. Am J Clin Nutr 82, 721-732.

22. Huang CH \& Misra SK (1991) Assessing nutritional adequacy of Americans based on individual food intake patterns. J Consum Stud Home Econ 15, 147-159.

23. US Department of Health and Human Services \& US Department of Agriculture (2005) Dietary Guidelines for Americans, 2005, 6th ed. Washington, DC: US Government Printing Office.

24. Ketchen DJ \& Shook CL (1996) The application of cluster analysis in strategic management research: an analysis and critique. Strategic Manage J 17, 441-458.

25. Hambrick DC (1983) An empirical typology of mature industrial-product environments. Acad Manage $J$ 26, 213-230.

26. Kimmons J, Gillespie C, Seymour J et al. (2009) Fruit and vegetable intake among adolescents and adults in the United States: percentage meeting individualized recommendations. Medscape J Med 11, 26.

27. Blanck HM, Gillespie C, Kimmons JE et al. (2008) Trends in fruit and vegetable consumption among US men and women, 1994-2005. Prev Chronic Dis 5, 1-10.

28. Putnam J, Allshouse J \& Kantor LS (2002) US per capita food supply trends: more calories, refined carbohydrates, and fats. Food Rev 25, 2-15.

29. US Department of Health and Human Services \& US Department of Agriculture (2005) The Report of the Dietary Guidelines Advisory Committee on Dietary Guidelines for Americans, 2005. Washington, DC: DHHS.

30. Billson H, Pryer JA \& Nichols R (1999) Variation in fruit and vegetable consumption among adults in Britain. An analysis from the dietary and nutritional survey of British adults. Eur J Clin Nutr 53, 946-952.

31. Agudo A \& Pera G (1999) Vegetable and fruit consumption associated with anthropometric, dietary and lifestyle factors in Spain. Public Health Nutr 2, 263-271.

32. Johansson L \& Andersen LF (1998) Who eats 5 a day? Intake of fruits and vegetables among Norwegians in relation to gender and lifestyle. J Am Diet Assoc 98, 689-691.

33. Bertail P \& Caillavet F (2008) Fruit and vegetable consumption patterns: a segmentation approach. Am J Agric Econ 90 , 827-842.

34. Bailey RL, Gutschall MD, Mitchell DC et al. (2006) Comparative strategies for using cluster analysis to assess dietary patters. J Am Diet Assoc 106, 1194-1200.

35. Dennison BA, Rockwell HL \& Baker SL (1998) Fruit and vegetable intake in young children. J Am Coll Nutr 17, 371-378.

36. Trudeau E, Kristal AR, Li S et al. (1998) Demographic and psychological predictors of fruit and vegetable intakes differ: implications for dietary interventions. J Am Diet Assoc 98, 1412-1417. 


\section{Appendix}
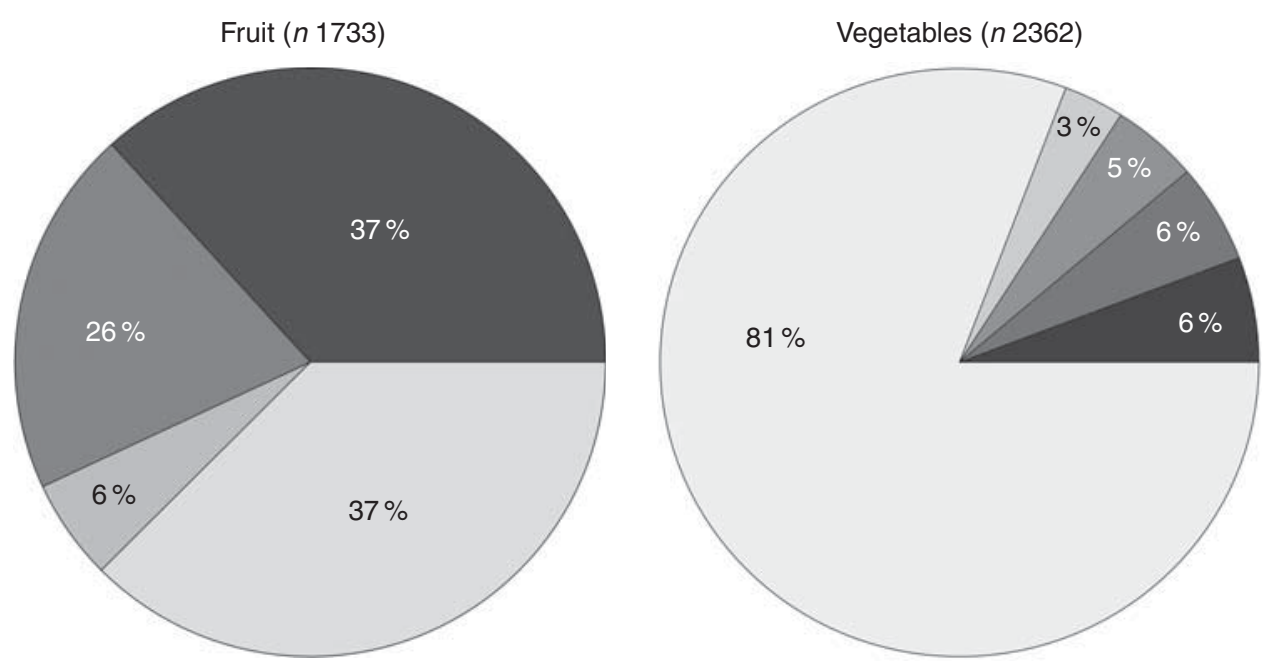

Fig. A1 Percentage of adults consuming exclusively one fruit/vegetable subgroup. Source: National Health and Nutrition Examination Survey 2005-2006 (fruit ( $n$ 1733): $\square$, only raw; $\square$, only juice; $\square$, only canned/frozen/dried/desserts; several subgroups; vegetables ( $n$ 2362): $\square$, only raw; $\square$, only cooked; $\square$, only in mixed dishes; $\square$, only fried; $\square$, several subgroups) 